\title{
Ectopic Expression of Multiple Microbial Rhodopsins Restores ON and OFF Light Responses in Retinas with Photoreceptor Degeneration
}

\author{
Yi Zhang, Elena Ivanova, Anding Bi, and Zhuo-Hua Pan \\ Department of Anatomy and Cell Biology, Wayne State University School of Medicine, Detroit, Michigan 48201
}

\begin{abstract}
By expressing channelrhodopsin-2 (ChR2) in inner retinal neurons, previous studies have demonstrated restoration of ON responses in the retina after the death of rod and cone photoreceptors. In this study, we report that the expression of halorhodopsin (HaloR), a light-driven chloride pump, can effectively restore OFF responses in inner retinal neurons of mice with retinal degeneration. We show that HaloR-expressing retinal ganglion cells respond to light with rapid hyperpolarization and suppression of spike activity. After termination of the light stimulus, their membrane potential exhibits a rapid rebound overshoot with robust sustained or transient spike firing. Furthermore, we show that coexpression of $\mathrm{ChR} 2 / \mathrm{HaloR}$ in retinal ganglion cells can produce $\mathrm{ON}$, OFF, and even $\mathrm{ON}-\mathrm{OFF}$ responses, depending on the wavelength of the light stimulus. Our results suggest that the expression of multiple microbial rhodopsins such as $\mathrm{ChR} 2$ and HaloR is a possible strategy to restore both $\mathrm{ON}$ and OFF light responses in the retina after the death of rod and cone photoreceptors.
\end{abstract}

\section{Introduction}

The severe loss of photoreceptor cells caused by retinal degenerative diseases such as retinitis pigmentosa (Weleber, 1994) can result in partial or complete blindness. As a new strategy to treat blindness caused by retinal degeneration, we previously demonstrated the functional expression of channelrhodopsin-2 (ChR2) in inner retinal neurons and the restoration of visual responses in mice after the death of rod and cone photoreceptors (Bi et al., 2006). Since ChR2 is a light-gated cation channel (Nagel et al., 2003), its expression can effectively convert inner retinal neurons into photosensitive cells that respond to light with membrane depolarization (Bi et al., 2006; Farah et al., 2007; Tomita et al., 2007; Lagali et al., 2008). However, visual information is processed in the retina through two parallel pathways: an ON pathway involving $\mathrm{ON}$ cells that respond to light increments with membrane depolarization or an increase in firing frequency, and an OFF pathway involving OFF cells that respond to light decrements with membrane depolarization or an increase in firing frequency (Werblin and Dowling, 1969; Kaneko, 1970) (for review, see Wässle, 2004). Furthermore, there are sustained and transient cells in both pathways characterized by their temporal light response properties. Some retinal ganglion cells also respond transiently to both light onset and offset and are termed

Received Jan. 12, 2009; revised June 10, 2009; accepted June 16, 2009.

This work was supported by National Institutes of Health Grant EY17130 to Z.-H.P. and Core Grant EY04068 to Department of Anatomy and Cell Biology at Wayne State University. We thank Dr. R. B. Needleman for his valuable comments, Dr. J. K. Lanyi for providing us with the native clone of pharaonis halorhodopsin, and Dr. R. Y. Tsien for providing us with the mCherry fluorescent protein CDNA.

Correspondence should be addressed to Dr. Zhuo-Hua Pan, Department of Anatomy and Cell Biology, Wayne State University School of Medicine, 540 East Canfield Avenue, Detroit, MI 48201. E-mail: zhpan@med.wayne.edu. DOI:10.1523/JNEUROSCI.0184-09.2009

Copyright (C) 2009 Society for Neuroscience $\quad 0270-6474 / 09 / 299186-11 \$ 15.00 / 0$
ON-OFF cells. The segregation of visual signals into ON and OFF pathways has been reported to enhance contrast sensitivity (Schiller et al., 1986). Sustained and transient pathways are believed to process signals related to the spatial and temporal aspects of visual images, respectively (Jacobs and Werblin, 1998; Boycott and Wässle, 1999). Although converting inner retinal neurons into ON cells might be sufficient to restore useful vision, restoration of both ON and OFF responses, as well as other natural light response properties of the retina, would be expected to achieve further improvements in vision.

One strategy to restore OFF responses in inner retinal neurons is to express a light sensor that can produce membrane hyperpolarization in response to light stimulation. Halorhodopsin (HaloR), a light-driven chloride ion pump from halobacteria (Lanyi, 1986), is a promising tool for this purpose (Han and Boyden, 2007; Zhang et al., 2007). Whether the expression of HaloR in inner retinal neurons can effectively restore OFF responses in the retina, however, remains unknown. Furthermore, it would be necessary to explore multiple possible approaches to restore both $\mathrm{ON}$ and OFF light responses in the degenerated retina.

In this study, we investigated the feasibility of restoring the OFF response to the retina by expressing HaloR in inner retinal neurons. We also examined the coexpression of HaloR and ChR2 in inner retinal neurons and their light response properties. Our results show that expression of HaloR can effectively convert non-photosensitive inner retinal neurons into OFF cells. Furthermore, both sustained and transient OFF responses mediated by HaloR can be generated. We also show that HaloR and ChR2 coexpressing cells can produce ON, $\mathrm{OFF}$, and $\mathrm{ON}-\mathrm{OFF}$ responses, depending on the illumination wavelength. 


\section{Materials and Methods}

DNA and viral vector constructs. Functional expression of HaloR was first verified in HEK293 cells with a native clone of pharaonis halorhodopsin, kindly provided by J. K. Lanyi (University of California, Irvine, Irvine, CA) (Lanyi et al., 1990). For the viral construct, a mammalian codonoptimized cDNA encoding an N-terminal fragment $\left(\mathrm{Met}^{1}-\mathrm{Asp}^{291}\right.$ ) of the native HaloR was chemically synthesized. The fusion chimera of HaloRmCherry was made by inserting the cDNA of a red fluorescent protein, mCherry, at the $3^{\prime}$ end of the HaloR coding fragment. The mCherry fluorescent protein cDNA was kindly provided by R.Y. Tsien (University of California, San Diego, La Jolla, CA) (Shaner et al., 2004). The Chop2green fluorescent protein (GFP) construct has been described previously (Bi et al., 2006). The viral expression constructs, recombinant adenoassociated viral 2 ( $r$ AAV2) - cytomegalovirus (CMV)-HaloR-mCherrywoodchuck post-transcriptional regulatory element (WPRE) and rAAV2-CMV-Chop2-GFP-WPRE, were made by subcloning the HaloR-mCherry and Chop2-GFP chimeras into a recombinant adenoassociated virus (serotype-2) (rAAV2) expression cassette containing a human CMV promoter, a WPRE, and a bovine growth hormone (BGH) polyadenylation sequence. Viral vectors were packaged and affinity purified at the Gene Therapy Program of the University of Pennsylvania.

Viral vector injection. All of the animal experiments and procedures were approved by the Institutional Animal Care and Use Committee at Wayne State University and were consistent with the National Institutes of Health Guide for the Care and Use of Laboratory Animals. Adult C57BL/6J mice aged 1-2 months and $r d 1 / r d 1$ mice aged $\sim 2-5$ months were anesthetized by intraperitoneal injection of ketamine $(120 \mathrm{mg} / \mathrm{kg})$ and xylazine $(15 \mathrm{mg} / \mathrm{kg})$. Using scissors, an incision was made under a dissecting microscope through the eyelid to expose the sclera. A small perforation was made with a needle in the sclera region posterior to the limbus, and $1.0 \mu \mathrm{l}$ of viral vector suspension at a concentration of $\sim 1-$ $9 \times 10^{11}$ genomic particles/ml or sham control (saline) was injected into the intravitreal space. One to four months after the viral vector injection, animals were killed by $\mathrm{CO}_{2}$ asphyxiation followed by decapitation for histological and electrophysiological experiments.

Histology. The expression of HaloR-mCherry fluorescence was examined in whole-mount retinas and retinal vertical sections. Retinas were fixed in the eyecups with $4 \%$ paraformaldehyde in PBS for $20 \mathrm{~min}$ at room temperature. Fluorescence was visualized under a Zeiss Axio or ApoTome fluorescence microscope. Images were captured using a digital camera.

Patch-clamp recordings. Patch-clamp recordings were performed on acutely dissociated cells and cells in retinal slices as described previously (Pan, 2000; Cui et al., 2003). The photoreceptor-mediated light response in retinal slices from wild-type retinas was bleached by bright light during slice preparation. This was confirmed by the absence of any significant light responses from uninfected retinal ganglion cells. No chromophore groups were added in any of the recordings as reported previously (Bi et al., 2006). The extracellular recording solution contained (in $\mathrm{mm}$ ) the following: $138 \mathrm{NaCl}, 1 \mathrm{NaHCO}_{3}, 0.3 \mathrm{Na}_{2} \mathrm{HPO}_{4}, 5 \mathrm{KCl}, 0.3 \mathrm{KH}_{2} \mathrm{PO}_{4}, 1.25$ $\mathrm{CaCl}_{2}, 0.5 \mathrm{MgSO}_{4}, 0.5 \mathrm{MgCl}_{2}, 5$ HEPES-NaOH, 22.2 glucose, with phenol red, $0.001 \% \mathrm{v} / \mathrm{v}$, adjusted to $\mathrm{pH} 7.2$ with $0.3 \mathrm{~N} \mathrm{NaOH}$. The electrode solution contained (in $\mathrm{mm}$ ) the following: $133 \mathrm{~K}$-gluconate, $7 \mathrm{KCl}, 4$ $\mathrm{MgCl}_{2}, 0.1$ EGTA, 10 HEPES, $0.5 \mathrm{Na}-\mathrm{GTP}$, and $2 \mathrm{Na}-\mathrm{ATP}$, pH adjusted with $\mathrm{KOH}$ to 7.4 . In voltage-clamp recordings, the membrane potential was clamped at $-70 \mathrm{mV}$. In current-clamp recordings, the membrane potential was held around $-70 \mathrm{mV}$, usually with a small negative holding current ranging from -2.5 to $-14 \mathrm{pA}$. The liquid junction potential was corrected. Curve fitting was performed by using ORIGIN (Microcal Software) programs.

Multielectrode array recordings. The multielectrode array recordings were performed based on previously described procedures (Tian and Copenhagen, 2003; Bi et al., 2006). Briefly, the retina was dissected and placed photoreceptor side down on a piece of nitrocellulose filter paper (Millipore Bioscience Research Reagents). The mounted retina was placed in the MEA-60 multielectrode array recording chamber of $30 \mu \mathrm{m}$ diameter electrodes spaced $200 \mu \mathrm{m}$ apart (Multi Channel System), with the ganglion cell layer facing the recording electrodes. The retina was continuously perfused in oxygenated extracellular solution at $34^{\circ} \mathrm{C}$ during all experiments. The extracellular solution contained (in mM) 124 $\mathrm{NaCl}, 2.5 \mathrm{KCl}, 2 \mathrm{CaCl}_{2}, 2 \mathrm{MgCl}_{2}, 1.25 \mathrm{NaH}_{2} \mathrm{PO}_{4}, 26 \mathrm{NaHCO}_{3}$, and 22 glucose, $\mathrm{pH} 7.35$ with $95 \% \mathrm{O}_{2}$ and $5 \% \mathrm{CO}_{2}$. Recordings usually began 60 min after the retina was positioned in the recording chamber. Light stimuli were projected onto the ganglion cell side of the retina. The interval between the onset of each light stimulus was 10-30 s. Signals were filtered between $200 \mathrm{~Hz}$ (low cutoff) and $20 \mathrm{kHz}$ (high cutoff). A threshold of $17-34 \mu \mathrm{V}$ was used to detect action potentials, and action potentials from individual neurons were determined via a standard expectation-maximization algorithm using off-line Sorter software (Plexon). The results were plotted using NeuroExplorer software (Nex Technologies).

Light stimulation. For dissociated cell recordings, light stimuli were generated by a $150 \mathrm{~W}$ xenon lamp-based scanning monochromator with a bandwidth of $10 \mathrm{~nm}$ (TILL Photonics), coupled to the microscope with an optical fiber. For retinal slice recordings, light responses were evoked by a $175 \mathrm{~W}$ xenon lamp-based illuminator (Lambda LS; Sutter Instrument) with a bandpass filter of 555-575 $\mathrm{nm}$ and projected to the top of the recording chamber through a liquid light guide. For multielectrode recordings of HaloR-mediated responses, light stimuli were generated by either the scanning monochromator or the $175 \mathrm{~W}$ xenon lamp-based illuminator with a bandpass filter of 420-590 nm. For multielectrode recordings of ChR2/HaloR-coexpressing retinas, light stimuli were generated by the scanning monochromator. The light intensity was attenuated by neutral density filters.

Chemicals. D-APV [D(-)-2-amino-5-phosphonopentanoic acid], L-APB [L-(+)-2-amino-4-phosphonobutyric acid], 6-cyano-7-nitroquinoxaline2,3-dione (CNQX), strychnine, and picrotoxinin were purchased from Sigma-Aldrich. Dihydro- $\beta$-erythroodine $(\mathrm{DH} \beta \mathrm{E})$ was purchased from Tocris Bioscience.

\section{Results}

AAV-mediated expression of HaloR in retinal neurons in vivo HaloR expression in inner retinal neurons was achieved using $r \mathrm{AAV}$ vectors. A viral expression cassette, $r \mathrm{AAV} 2-\mathrm{CMV}-\mathrm{HaloR}-$ mCherry-WPRE, was made by inserting a fusion chimera of HaloR and a red fluorescence protein, mCherry, into a rAAV serotype-2 expression cassette containing the CMV promoter (Fig. 1A). The viral vectors carrying HaloR-mCherry were injected into the intravitreal space of the eyes of adult C57BL/6 J mice. One month after viral injection, bright red fluorescence was observed in all of the retinas of the eyes injected with virus $(n=$ 14 ) but not in the retinas of the sham-injected eyes $(n=4)$. When viewed at low magnification, red fluorescence appeared uniform throughout the retina in the majority of the eyes (10 of 14). Figure $1, B$ and $C$, shows representative images taken from retinal whole-mounts at low (Fig. $1 B$ ) and high (Fig.1C) magnification. Figure $1 D$ shows a representative image taken from a retinal vertical section. HaloR-mCherry expression was predominantly observed in third order retinal neurons, amacrine cells, and ganglion cells. Expression was frequently found in horizontal cells (Fig. $1 D$, arrow) but was only occasionally seen in photoreceptor cells (Fig. $1 D$, arrowhead) and bipolar cells.

\section{Properties of HaloR-mediated current in inner retinal neurons}

We first examined the properties of HaloR-mediated current responses in retinal neurons using whole-cell patch-clamp recordings. The recordings were made from acutely dissociated cells (Fig. 2A). Consistent with the properties of HaloR reported previously in the Xenopus oocyte expression system (Seki et al., 2007) and in other neurons of the CNS (Han and Boyden, 2007; Zhang et al., 2007), sustained outward currents were elicited in mCherry-positive cells in voltage clamp by light up to a wavelength of $650 \mathrm{~nm}(n=24)$. No light-evoked outward currents 
were observed in mCherry-negative cells from the eyes injected with virus $(n=6)$. The cells were most sensitive to wavelengths of $\sim 570 \mathrm{~nm}$, as shown in a representative recording in Figure $2 B$. These properties are different from those with ChR2, which responds to light up to a wavelength of $580 \mathrm{~nm}$, with the most sensitive wavelengths occurring at $\sim 460 \mathrm{~nm}$ (Nagel et al., 2003; Boyden et al., 2005; Bi et al., 2006). As shown in Figure $2 C$, the magnitude of the HaloR-mediated current depended on the light intensity. A detectable current $(2.0 \pm 1.2 \mathrm{pA}$; mean \pm $\mathrm{SD} ; n=6$ ) was observed at a light intensity of $5.8 \times 10^{16}$ photons $\mathrm{cm}^{-2} \mathrm{~s}^{-1}$. For comparison, under the same recording conditions, a detectable current $(3.9 \pm 2.0$ $\mathrm{pA}$; mean $\pm \mathrm{SD} ; n=6$ ) for ChR2 was observed at a light intensity of $3.0 \times 10^{15}$ photons $\mathrm{cm}^{-2} \mathrm{~s}^{-1}$, which is $\sim 20$-fold lower than that required for HaloR. The fitted light intensity-response curve of HaloR is shown in Figure $2 D$ (in red). The curve shows a rightward shift compared with the curve of ChR2 (in blue) (Bi et al., 2006).

We next examined the light response kinetics of HaloR and compared them to those of ChR2. Consistent with previous studies in other neurons in the CNS (Han and Boyden, 2007; Zhang et al., 2007), the activation and deactivation of HaloRmediated current were very fast. Moreover, both the activation and deactivation kinetics of HaloR were found to be even faster than those of ChR2. Figure $3 A$ shows the superimposed traces of HaloR(dark) and ChR2- (gray) mediated currents. For comparison, the ChR2mediated current was inverted and normalized to the peak current of HaloR. The initial phase of the current traces with respect to light onset is shown in Figure $3 B$ on an expanded time scale. The traces of both HaloR (dark) and ChR2 (gray) were fitted by an exponential function (red for HaloR and blue for ChR2), with a single activation and inactivation constant (Fig. 3B). The activation time constant versus light intensity is plotted in Figure $3 C$. The activation kinetics for both HaloR and ChR2 were light intensitydependent, but the activation constant of HaloR was faster than that of ChR2 throughout the intensity range tested. The normalized decay phase of the current traces after light offset is shown in Figure $3 D$. The deactivation time constant versus light intensity for HaloR (red) and ChR2 (blue) is plotted in Figure 3E. The deactivation of HaloR was also markedly faster than that of ChR2. Thus, similar to ChR2, HaloR can rapidly modulate the membrane potential of neurons by regulating the influx of chloride ions in response to light.

\section{Properties of HaloR-mediated voltage responses in inner retinal neurons}

We further examined HaloR-mediated voltage responses in current-clamp recordings. The recordings were made on cells in retinal slices as well as on acutely isolated cells. In retinal slices, the recordings were made from mCherry-positive cells located in the ganglion cell layer $(n=13)$. Figure $4, A$ and $B$, shows two representative recordings from retinal slices in response to incremental light intensities. For comparison, the HaloR-mediated currents for the cell shown in Figure $4 \mathrm{~A}$ are also illustrated. Detectable membrane hyperpolarization was again observed at a light intensity of $\sim 10^{16}$ photons $\mathrm{cm}^{-2} \mathrm{~s}^{-1}$. The magnitude of the membrane hyperpolarization was also dependent on light intensity. Light stimulation at a higher intensity evoked a marked membrane hyperpolarization. Moreover, although spontaneous spiking at rest was suppressed under our recording conditions by holding the membrane potential at approximately $-70 \mathrm{mV}$ (see Materials and Methods), after termination of the light stimulus, the membrane potential displayed a rapid rebound accompanied by robust spike firing. Interestingly, based on the properties of the rebound response, we observed two groups of spiking cells: a group of sustained spiking cells (Fig. $4 \mathrm{~A}$ ) and a group of transient spiking cells (Fig. $4 B$ ). We also found that the membrane potential of the sustained spiking cells $(n=4)$ exhibited an initial large hyperpolarization followed by a relaxation or voltage sag during 


\section{A}
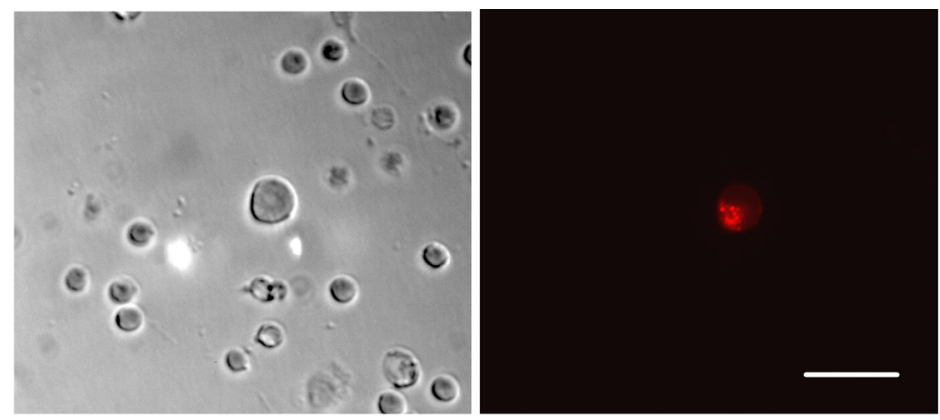

B
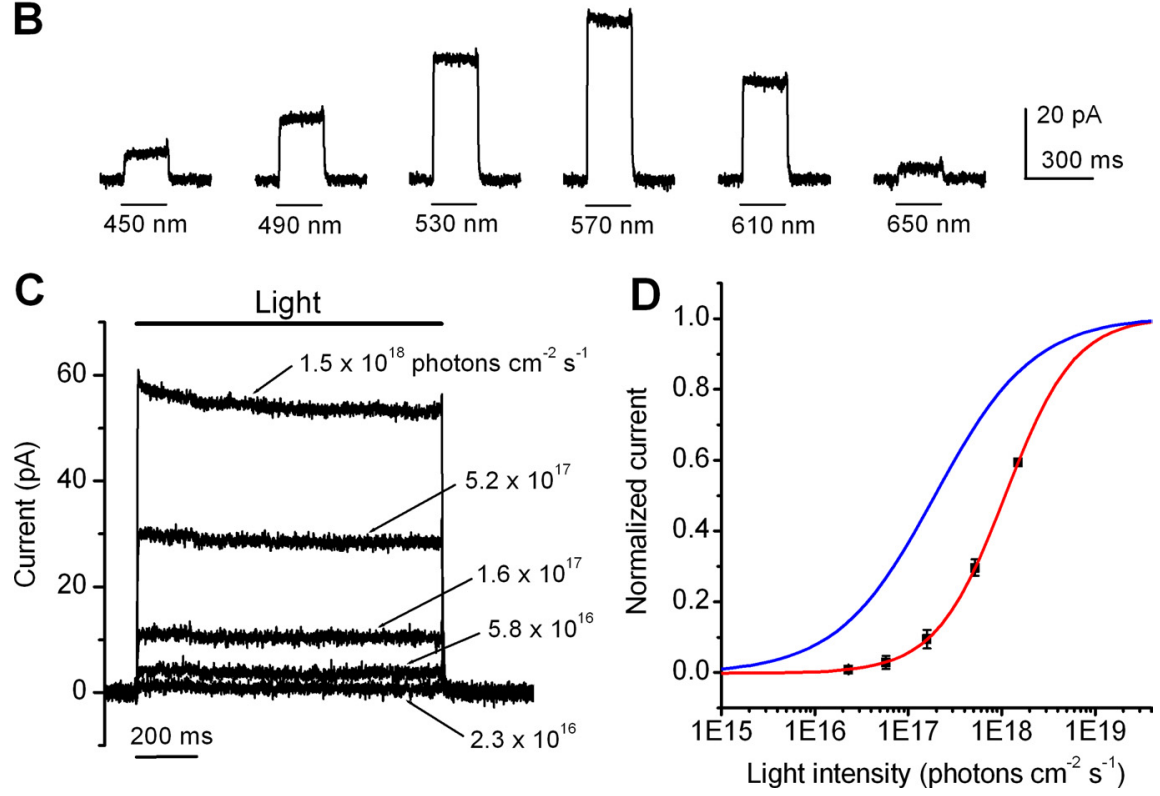

Figure 2. Properties of HaloR-mediated currents. $\boldsymbol{A}$, Differential interference contrast (left) and fluorescence (right) images were taken of a HaloR-mCherry-positive dissociated retinal neuron. Scale bar, $25 \mu \mathrm{m}$. B, HaloR-mCherry-positive cells responded to light stimuli of various wavelengths. The cells were most sensitive to wavelengths of $\sim 570 \mathrm{~nm}$. $C$, HaloR-mediated currents were elicited by various light intensities at a wavelength of $570 \mathrm{~nm}$. D, The light intensity response curve (in red) is shown for HaloR-mediated currents. The data points (mean \pm SD; $n=6$ cells) were fitted with a single logisticfunction (in red): $y(x)=y_{0} /\left[1+\left(x_{1 / 2} / x\right)^{n}\right]$ using nonlinearleast squares fitter, wherethe parameter of $x_{1 / 2}$ represents the light intensity to producing a half-saturated current; $n$, the Hill coefficient; and $y_{0}$, the saturated current. No constrain was used to the parameters during curve fitting. The best-fit curve was then normalized by assigning the parameter of $y_{0}$ to 1 . For comparison, the light-intensity response curve for ChR2-mediated currents measured at a wavelength of $460 \mathrm{~nm}$ (in blue) is also shown (Bi et al., 2006). All recordings were acquired at a holding potential of $-70 \mathrm{mV}$.

light stimulation (Fig. $4 A$, arrows). For the transient spiking cells $(n=9)$, this relaxation or voltage sag was small or absent. These properties were also observed in acutely isolated cells $(n=16)$, indicating that they are intrinsic properties of the cells. Regardless of the underlying mechanisms, our results indicate that the expression of HaloR in retinal neurons is capable of converting non-light-sensitive inner retinal neurons, including retinal ganglion cells, into sustained or transient OFF cells.

Figure $4 C$ shows a recording of the voltage-response to repeated light stimulation from the same cell shown in Figure $4 \mathrm{~A}$. The membrane potential was hyperpolarized during light stimulation and depolarized after termination of the light, with robust sustained spike firing. Figure $4 D$ shows recordings of a transient spiking cell to repeated light stimulation with three different frequencies of 5 (top), 10 (middle), and $25 \mathrm{~Hz}$ (bottom). The membrane potential and spike firing of this cell were able to follow the light modulation up to $25 \mathrm{~Hz}$.

We also examined whether HaloR-expressing cells could effectively suppress membrane depolarization or spike firing of an excited cell. To this end, a series of incremental current injections was applied to elicit membrane depolarization and/or spike firing in current-clamp recordings, and a light stimulus was applied during the current injection. Figure 4, $E$ and $F$, shows recordings from two representative cells. The light stimulus was able to effectively suppress the membrane depolarization or spike firing driven by the current injections. After termination of the light, the membrane potential once again rebounded and displayed sustained (Fig. $4 E$ ) or transient (Fig. $4 F$ ) spike firing.

\section{HaloR-mediated light responses of retinas in photoreceptor-deficient $r d 1 / r d 1$ mice}

To further demonstrate that the expression of HaloR is capable of restoring OFF responses to retinas after photoreceptor degeneration, we studied the expression and properties of HaloR-mediated light responses in $r d 1 / r d 1$ mice (Bowes et al., 1990), a photoreceptor degeneration model with a null mutation in a cyclic GMP phosphodiesterase, PDE6, similar to some forms of retinitis pigmentosa in humans (McLaughlin et al., 1993). Because of rapid retinal degeneration, the $r d 1 / r d 1$ mice are effectively blind by $3-4$ weeks of age (Jiménez et al., 1996; Stasheff, 2008). We performed experiments on animals ranging in age from 3 to 7 months and at $1-4$ months after virus injection.

Similar to the results in wild-type animals, bright red fluorescence was observed in the retinas of the eyes injected with virus, predominately in cells located in the retinal ganglion cell layer (Fig. $5 A-$ $C)$. Interestingly, this expression pattern was different from that seen in wild-type mice, because fewer second-order cells and amacrine cells were infected in $\mathrm{rdl} /$ $r d 1$ mice. The loss of expression in more distal cells in the retina of $r d 1 / r d 1$ mice is likely in part caused by the remodeling of inner retinal neurons after retinal degeneration (Strettoi and Pignatelli, 2000; Jones et al., 2003). Different background strains between the wild-type (C57BL/6J) and $r d 1 / r d 1(\mathrm{C} 3 \mathrm{H} / \mathrm{HeJ})$ mice could also contribute to the difference.

We examined light-evoked spike activity from HaloRinfected retinas of $r d 1 / r d 1$ mice using multielectrode array recordings in whole-mount retinas. Most neurons recorded with this method have been reported to be retinal ganglion cells (Rentería et al., 2006). Consistent with the whole-cell patch-clamp recordings from acutely isolated cell and retinal slice preparations, HaloR-mediated OFF responses were observed in HaloRtransfected retinas $(n=9)$ but not in sham-injected retinas $(n=4)$. Again, both sustained and transient OFF responses were observed. Figure $5 D$ shows the response of a sustained cell to four incremental light stimuli. In each panel, a single raw trace of the spike activity (top), a raster plot of 30 consecutive recordings (middle), and an averaged spike rate histogram (bottom) are shown. This cell showed tonic spontaneous spike activity in darkness. When the intensity of the light stimulus was increased, the 
spike frequency decreased during light stimulation but markedly increased after termination of the light. Figure $5 E$ shows the mean spike frequency during light $\mathrm{ON}$ (squares), the mean spike frequency after termination of the light (circles), and the peak frequency (triangles) versus light intensity. Figure $5 F$ shows sample recordings from a transient cell. Again, the transient OFF response was markedly increased when the light intensity increased. The peak frequency (triangles) and the mean frequency (circles) after termination of the light versus light intensity are shown in Figure 5G. Application of AMPA/kinate receptor antagonist CNQX $(25 \mu \mathrm{M})$, NMDA receptor antagonist D-APV $(25 \mu \mathrm{M})$, and mGluR6 receptor agonist L-APB $(10 \mu \mathrm{M})(n=5)$ had no effect on the HaloR-mediated light responses, although spontaneous activity in some cells was reduced (data not shown). Furthermore, no effect was seen with the addition of glycine receptor inhibitor strychnine $(2 \mu \mathrm{M}), \mathrm{GABA}_{\mathrm{A}} / \mathrm{GABA}_{\mathrm{C}}$ receptor inhibitor picrotoxinin $(100 \mu \mathrm{M})$, and nicotinic receptor inhibitor $\mathrm{DH} \beta \mathrm{E}(20 \mu \mathrm{M})$ $(n=1$ retina). These results indicate that the light-mediated suppression of tonic activity and the generation of the OFF response could not originate from presynaptic inputs, either from potentially surviving rod and cone photoreceptors or HaloR-expressing presynaptic cells. The reduction in spontaneous activity observed in some cells after CNQX, D-APV, and L-APB application is likely caused by the blockade of the spontaneous presynaptic excitatory inputs. We did not observe light responses of the intrinsically light-sensitive ganglion cells, mediated by melanopsin. This is likely because of the sparseness of the melanopsin-expressing ganglion cells in the retina and the slow onset of melanopsin-mediated light responses (Hattar et al., 2002; Tu et al., 2005). Even if they were encountered in our recordings, their responses would mostly occur beyond our data acquisition time frame (1.8 s after light onset).

To provide a quantitative measure of the temporal properties of the HaloR-mediated OFF responses, for each cell we calculated a sustained and transient index (STI) by dividing the mean spike frequency during the second $400 \mathrm{~ms}$ by that during the first 400 $\mathrm{ms}$ after termination of the light stimulus. Using this measurement system, the STI value of a transient cell (with no or little spiking activity during the second $400 \mathrm{~ms}$ after termination of the light stimulus) would be equal to or close to 0 . The STIs for the cells shown in Figure 5, $D$ and $F$, were 0.64 and 0.02 , respectively. Figure $5 H$ shows six additional sample recordings along with their STIs. The distribution of STIs for 160 recorded cells is shown in Figure $5 I$.

We also examined the effect of light duration on the HaloRas mean $\pm S D(n=6)$.

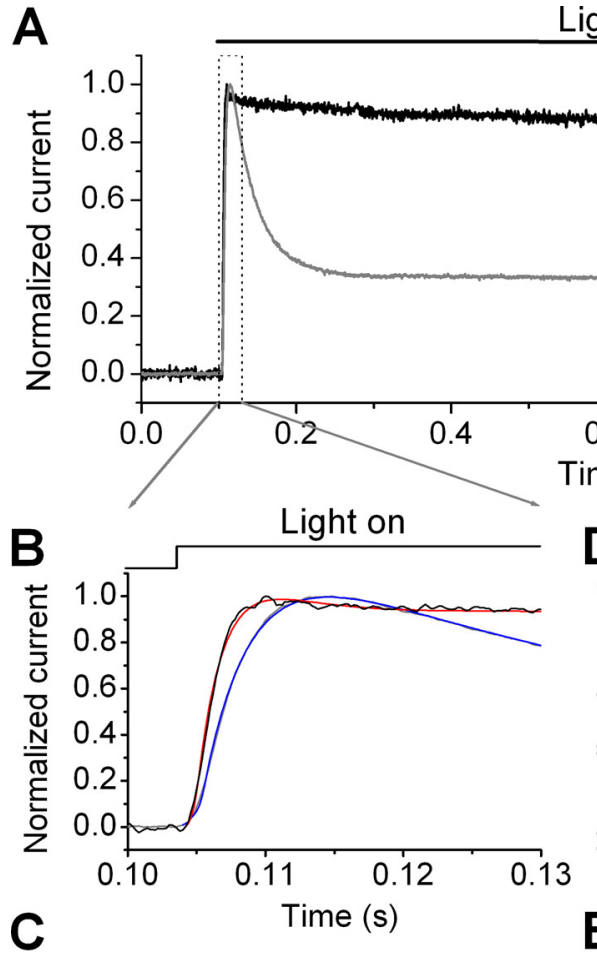

Light
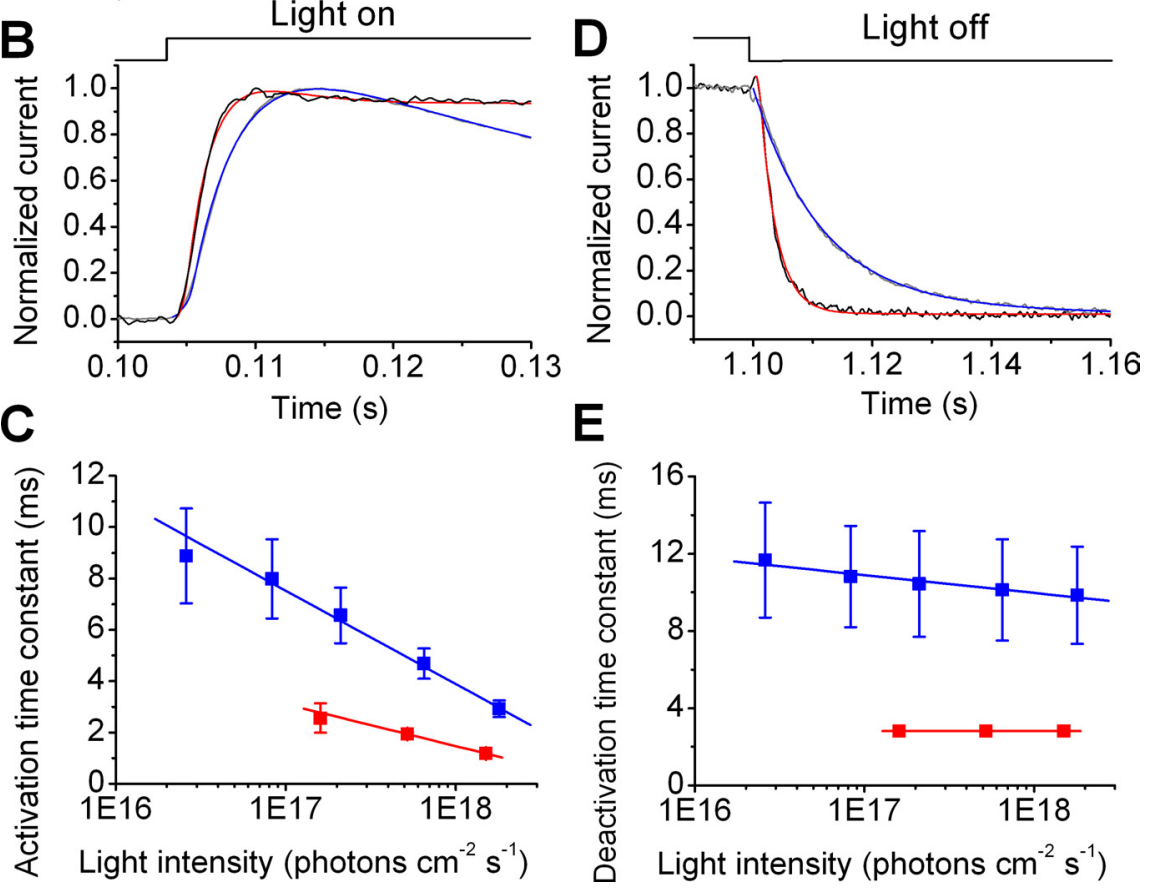

Figure 3. Comparison of the response kinetics of HaloR- and ChR2-mediated currents. $A$, A superposition of the HaloR- and ChR2-mediated currents elicited by light at wavelengths of 460 and $580 \mathrm{~nm}$, respectively, is shown. For comparison, the ChR2mediated current (in gray) was inverted and normalized to the peak HaloR current (in black). $\boldsymbol{B}$, Current traces of HaloR- and $a_{2}\left[\exp \left(-t / \tau_{2}\right)\right]$, where $\tau_{1}$ and $\tau_{2}$ represent the activation and inactivation time constants, respectively. $C$, The relation列 she red and blue curves show the fitting of the HaloR-and ChR2-mediated current traces, respectively, by a Iight intensity and the deactivation time constant for HaloR- (in red) and ChR2- (in blue) mediated currents was determined from the fitting shown in $\boldsymbol{C}$. All recordings were made at a holding potential of $-70 \mathrm{mV}$. The data points in $\boldsymbol{C}$ and $\boldsymbol{E}$ are shown

mediated rebound OFF spiking responses. Figure $6 A$ shows the HaloR-mediated OFF responses of a cell to five different light stimuli with durations of $1000,200,100,50$, and $20 \mathrm{~ms}$. The rebound OFF spiking response could be evoked by a light pulse as short as $20 \mathrm{~ms}$ (Fig. $6 \mathrm{~A}$, last panel), although both the peak and mean spike frequencies were reduced with the decrease of light duration (Fig. 6B). We further examined the temporal modulation of the HaloR-mediated spike firing. As shown in Figure $6 C$, most of the recorded cells could follow light pulses up to $10 \mathrm{~Hz}$ (8 of 12).

Together, these results further demonstrate that the expression of HaloR can convert non-light sensitive retinal ganglion cells into sustained and transient OFF cells in mice with retinal 

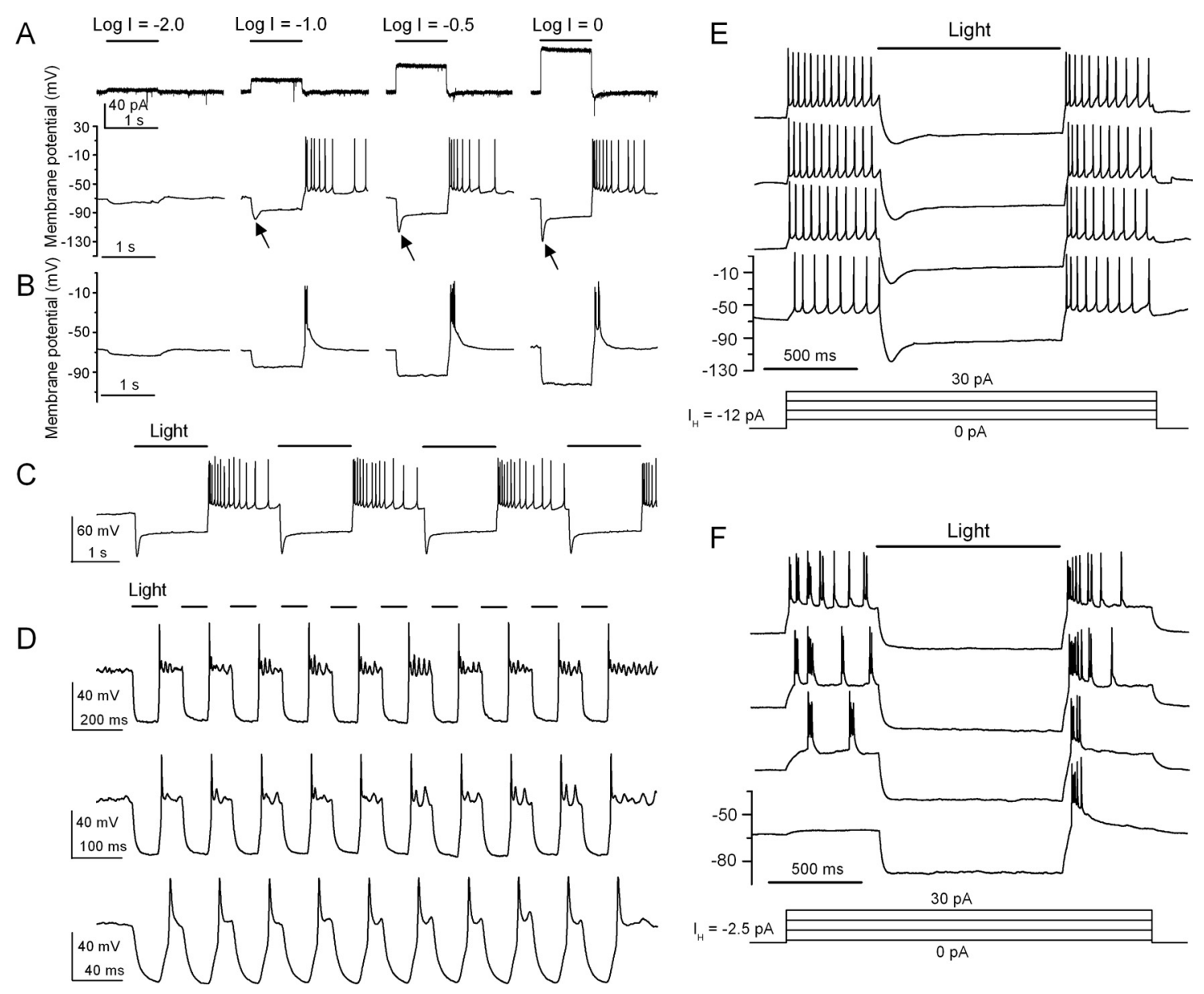

Figure 4. Properties of light-evoked voltage responses in HaloR-mCherry-expressing retinal neurons. $A, B$, Representative recordings are shown for HaloR-mediated voltage responses of two different cells that showed sustained $(\boldsymbol{A})$ and transient ( $\boldsymbol{B})$ OFF responses. For comparison, the current traces of the cell in $\boldsymbol{A}$ are also shown (top). Responses were elicited by four incremental light intensities. During light stimulation, the membrane potential was rapidly hyperpolarized to a magnitude that was dependent on the light intensity. After termination of the light stimulus, the membrane potential showed a rapid rebound overshoot, which evoked sustained $(\boldsymbol{A})$ or transient $(\boldsymbol{B})$ spike firing. The arrows in $\boldsymbol{A}$ indicate voltage sag. $\boldsymbol{C}$, Voltage responses elicited by repeated light pulses $(0.33 \mathrm{~Hz}$ ) recorded from the same cell shown in $\boldsymbol{A}$. D, Recordings of a transient spiking cell to repeated light stimulation with three different frequencies of 5 (top), 10 (middle), and $25 \mathrm{~Hz}$ (bottom). Note the different time scales. The holding currents for the cells shown in $\boldsymbol{A}, \boldsymbol{B}$, and $\boldsymbol{D}$ are $-9.0,-2.5$, and $-10 \mathrm{pA}$, respectively. $\boldsymbol{E}$, $\boldsymbol{F}$, Representative recordings of HaloR-mediated inhibition of membrane depolarization and spiking elicited by current injection. Cells were depolarized by a series of incremental current pulses, and light stimulation effectively suppressed both membrane depolarization and spike activity. All recordings were made from morphologically identified ganglion cell in retinal slices. The light intensity in $\boldsymbol{A}$ and $\boldsymbol{B}$ without neutral density filters (Log $\mathrm{I}=0)$ and in $\boldsymbol{C}-\boldsymbol{F}$ was $5.1 \times 10^{18}$ photons $\mathrm{cm}^{-2} \mathrm{~s}^{-1}$.

degeneration. Moreover, HaloR-mediated OFF responses can encode light intensity changes in terms of spike firing rate with high temporal resolution.

\section{Coexpression of HaloR- and ChR2-mediated light responses}

Our previous studies of ChR2 (Bi et al., 2006) and the results of HaloR in this study suggest that expression of ChR2 and HaloR in $\mathrm{ON}$ and OFF inner retinal neurons, respectively, is a possible approach to restore both $\mathrm{ON}$ and OFF light responses after photoreceptor degeneration. This approach, however, would require targeting of ChR2 and HaloR to ON and OFF inner retinal neurons, respectively. To explore an alternative approach, we investigated whether restoration of $\mathrm{ON}$ and OFF responses in inner retinal neurons such as retinal ganglion cells could be achieved by coexpression of ChR2 and HaloR.

In this set of experiments, viral vectors carrying HaloRmCherry and ChR2-GFP, both driven by CMV promoter, were coinjected into the eyes of adult $r d 1 / r d 1$ mice. As shown in Figures $7 A-C$ in retinal whole mounts, colocalization of mCherry and GFP was observed in the majority of the transfected cells located in the retinal ganglion cell layer. It is noteworthy that the expression of ChR2-GFP was predominantly on the plasma membrane, whereas significant expression of HaloR-mCherry was seen in intracellular organelles (see insert images at higher magnification). Similar observations have been reported in other neurons in primary culture and transgenic mice (Gradinaru et al., 2008; Zhao et al., 2008). It has been reported that the problem of poor membrane targeting could be eliminated by adding a signal peptide sequence and an endoplasmic reticulum export motif (Gradinaru et al., 2008; Zhao et al., 2008).

HaloR- and ChR2-mediated light responses were observed in the majority of cotransfected retinas ( $n=7$ of 9). Figure 7, $D$ and $E$, shows recordings from two representative cells using multielectrode array recordings from retinal whole mounts. As illustrated in Figure 7, D and $E$, a light stimulus at $460 \mathrm{~nm}$ evoked sustained ON responses in both cells (Figs. 7D, E, left panels), whereas a $580 \mathrm{~nm}$ light stimulus produced a sustained OFF response in the first cell (Fig. $7 D$, right panel) but a transient OFF response in the second cell (Fig. 7E, right panel).

We also examined the dependence of the response pattern on light wavelength $(n=2$ retinas). Figure $7 F$ shows raw traces of spike activity from a representative cell elicited by light at wave- 

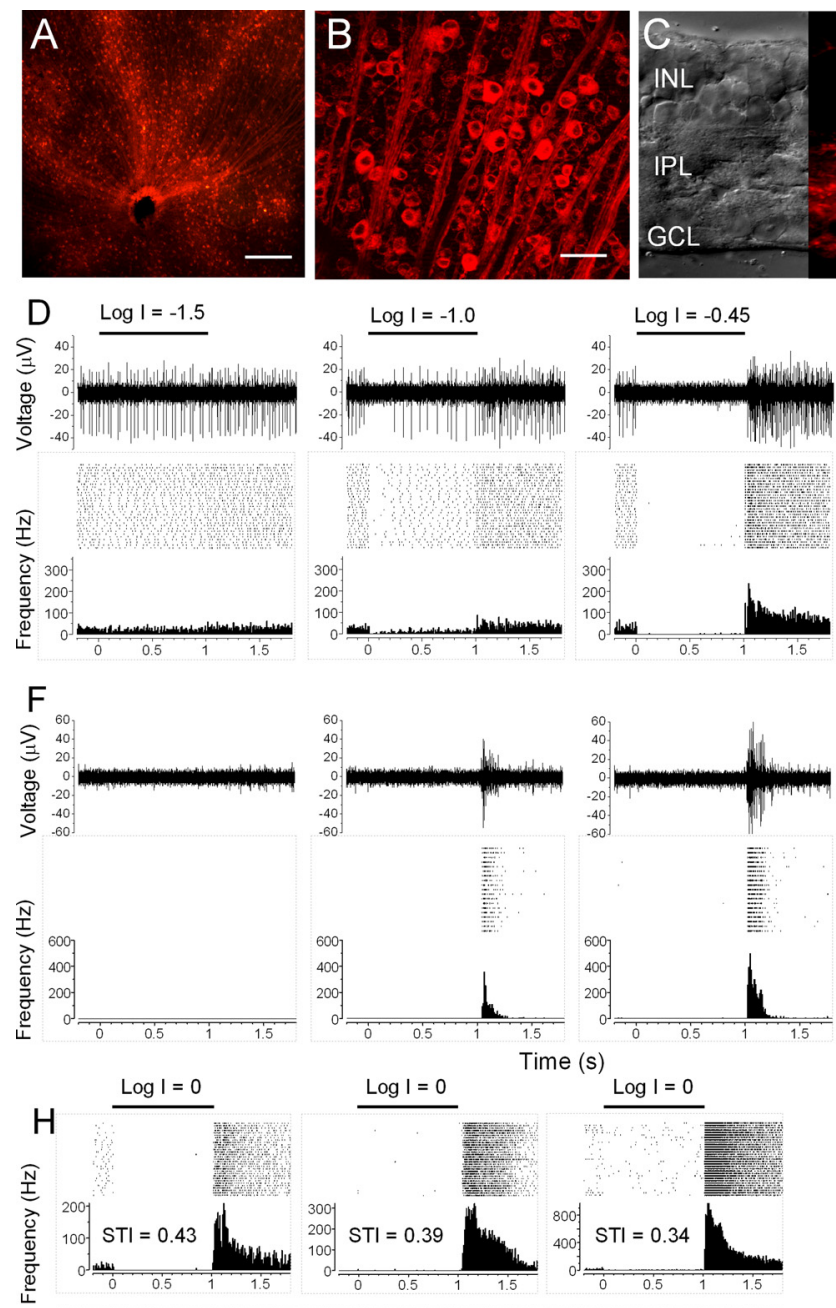

$\log I=0$
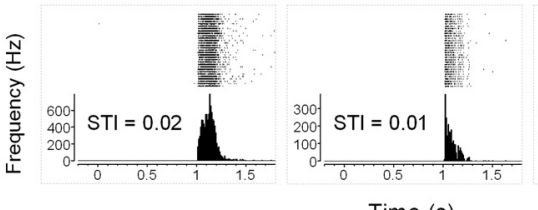

Time (s)
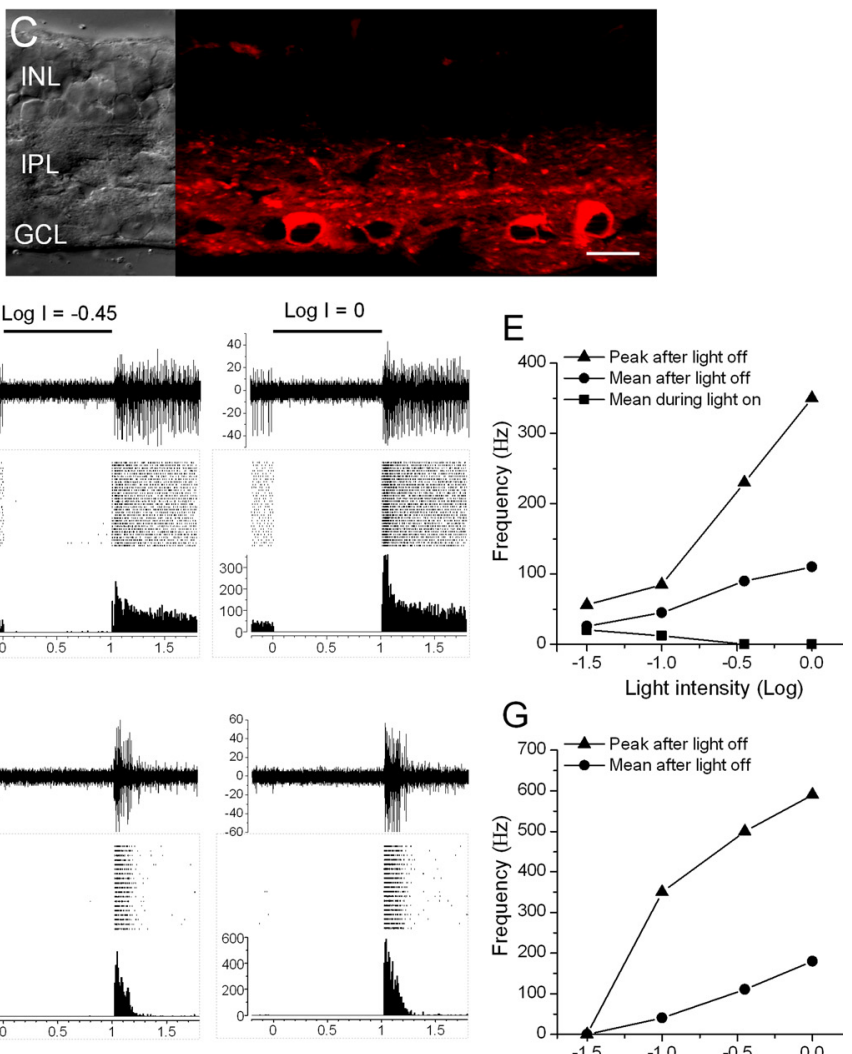

G

Light intensity ( Log)

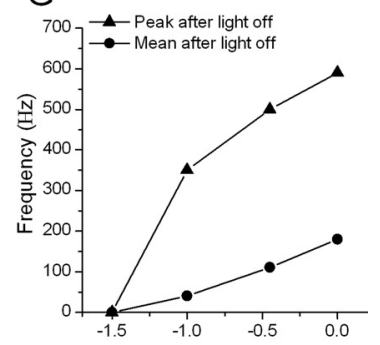

Light intensity (Log)

I

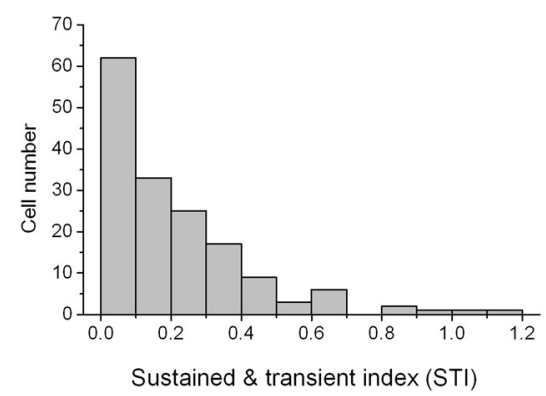

Figure 5. Multielectrode array recordings of HaloR-mediated spike responses from $r d 1 / r d 1$ retinas. $\boldsymbol{A}, \boldsymbol{B}$, HaloR-mCherry fluorescence in an $r d 1 / r d 1$ retinal whole-mount at low $(\boldsymbol{A})$ and high $(\boldsymbol{B})$ magnification. $\boldsymbol{C}$, HaloR-mCherry fluorescence (right) and differential interference contrast (left) images were taken from a retinal vertical section. Scale bars: $\boldsymbol{A}, 200 \mu \mathrm{m} ; \boldsymbol{B}, 50 \mu \mathrm{m} ; \boldsymbol{C}, 25 \mu \mathrm{m}$. $\boldsymbol{D}$, Sample recordings of HaloR-mediated spike activity from a sustained OFF-type cell in response to four incremental light intensities. In each panel, a single trace of light-evoked spike activity, a raster plot of 30 consecutive recordings, and an averaged spike rate histogram are shown in the top, middle, and bottom panels, respectively. $\boldsymbol{E}$, The mean spike frequency (squares) during light $0 \mathrm{~N}$, the peak (triangles) and mean (circles) spike frequency after termination of the light stimulus versus light intensity for the cell shown in $\boldsymbol{D}$. $\boldsymbol{F}$, Sample recordings of HaloR-mediated spike activity from a transient OFF-type cell were taken under the same recording conditions as in $\mathbf{D}$. $\mathbf{G}$, The peak (triangles) and mean (circles) spike frequency after termination of the light stimulus versus light intensity for the cell shown in $\boldsymbol{F}$. The mean frequency in $\boldsymbol{E}$ and $\boldsymbol{G}$ was calculated over a period of $800 \mathrm{~ms}$ after termination of the light stimulus. $\boldsymbol{H}$, Six representative cells are shown along with their STIs. $I$, The distribution plot of STIs was generated from 160 recorded cells. All of the recordings were made in the presence of $25 \mu \mathrm{M}$ CNQX, $25 \mu \mathrm{M}$ D-APV, and $10 \mu \mathrm{M} \mathrm{L-APB}$. The light intensity in $\boldsymbol{D}$, $\boldsymbol{F}$, and $\boldsymbol{H}$ without neutral density filters $(\log \mathrm{I}=0)$ was $1.6 \times 10^{17}$ photons $\mathrm{cm}^{-2} \mathrm{~s}^{-1}$.

lengths of 480,520,530, and $580 \mathrm{~nm}$. A raster plot of the spike activity in response to light wavelengths ranging from 380 to 620 $\mathrm{nm}$ is shown in Figure 7G. Light stimuli at wavelengths up to 500 $\mathrm{nm}$ elicited a sustained ON response, whereas wavelengths of 540-620 nm elicited a transient or sustained OFF response. Interestingly, light stimuli at intermediate wavelengths, $\sim 520-530$ $\mathrm{nm}$, could elicit a transient $\mathrm{ON}-\mathrm{OFF}$ response in a portion of the recorded cells ( 15 of 57). The transient ON-OFF responses likely resulted from a transition of ChR2-mediated excitation to HaloR-mediated inhibition. These results indicate that coexpression of ChR2 and HaloR in retinal ganglion cells can generate
ON, OFF, and even ON-OFF responses, depending on the wavelength of light stimulation.

\section{Discussion}

In this study, we have demonstrated that the expression of HaloR could effectively convert light-insensitive inner retinal neurons, including retinal ganglion cells, into OFF cells in both normal and photoreceptor-deficient retinas.

Consistent with recent studies in other mammalian neurons (Han et al., 2007; Zhang et al., 2007; Zhao et al., 2008), we show 

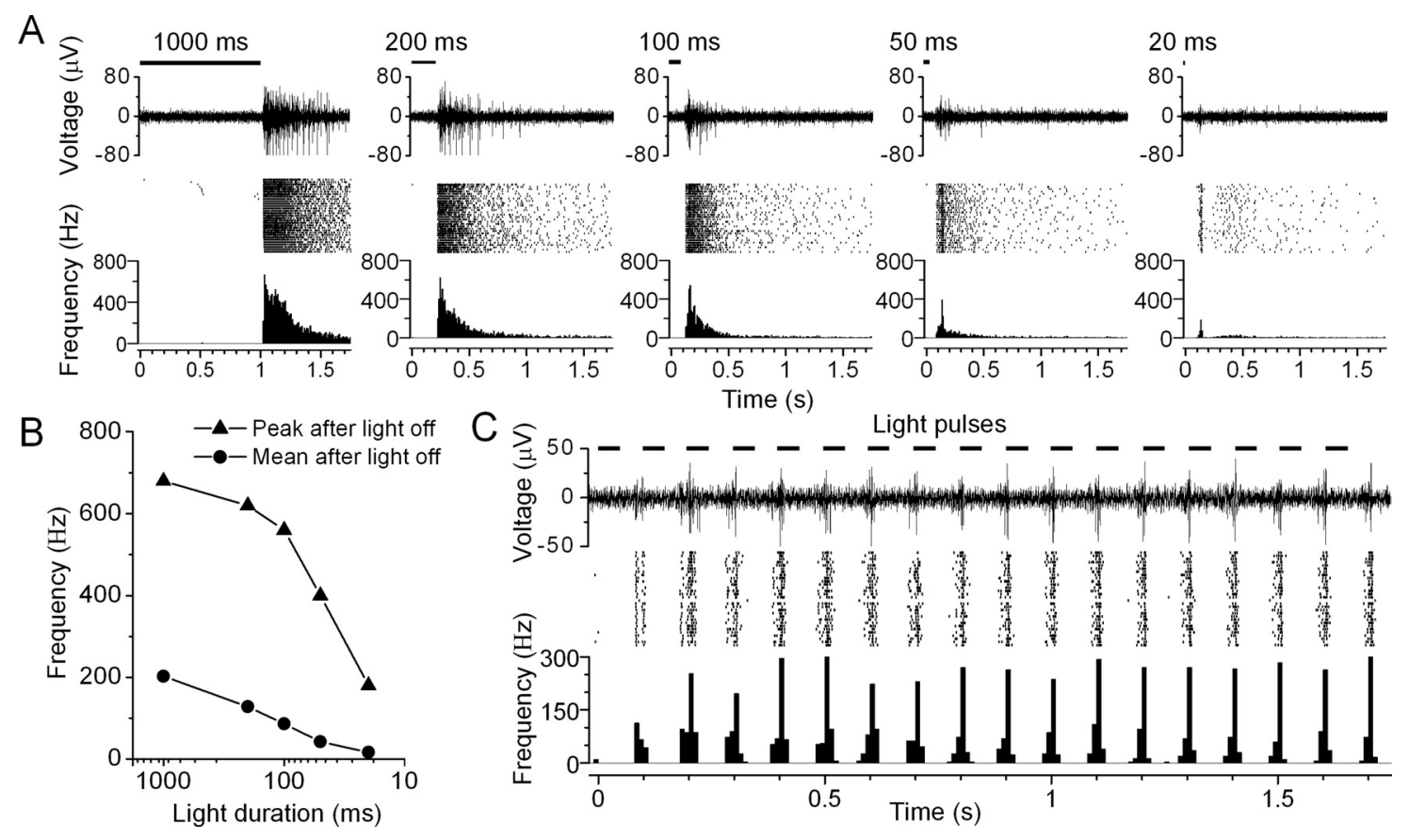

Figure 6. Multielectrode array recordings of the temporal modulation of HaloR-mediated spike responses from $r d 1 / r d 1$ retinas. $A$, HaloR-mediated rebound 0 FF spiking responses were elicited by light pulses with durations of $1000,200,100,50$, and $20 \mathrm{~ms}$. In each panel, a single trace of spike activity, a raster plot, and an averaged spike rate histogram are shown. $\boldsymbol{B}$, The peak (triangles) and mean (circles) spike frequency after termination of the light stimulus versus light duration for the cell shown in $A$. The mean frequency was calculated over a period of $1.8 \mathrm{~s}$ after termination of the light stimulus. C, Recordings of the same cell shown in $\boldsymbol{A}$ to light pulses at $10 \mathrm{~Hz}$ ( $50 \mathrm{~ms}$ on and $50 \mathrm{~ms}$ off). A single trace of spike activity (top), a raster plot (middle), and an averaged spike rate histogram (bottom) are shown. The recordings were made in the presence of $25 \mu \mathrm{M}$ CNQX, $25 \mu \mathrm{m} \mathrm{D}-\mathrm{APV}, 10 \mu \mathrm{M} \mathrm{L-APB}$, strychnine (2 $\mu \mathrm{M})$, picrotoxinin (100 $\mu \mathrm{M})$, and DH $\beta E(20 \mu \mathrm{M})$. The light intensity was $5.1 \times 10^{18}$ photons $\mathrm{cm}^{-2} \mathrm{~s}^{-1}$.

the feasibility of functional expression of HaloR in inner retinal neurons in vivo. Our results also show that activation of HaloR can effectively drive membrane hyperpolarization and suppress membrane depolarization. In addition, both the activation and deactivation kinetics of HaloR are fast and even faster than those of ChR2. The latter is rather surprising given that HaloR is a lightdriven pump (Lanyi, 1986; Kolbe et al., 2000). Whatever the mechanism, the pump-based microbial rhodopsins can also serve as powerful tools to manipulate membrane potentials of neurons in the CNS.

However, we found that HaloR was less sensitive to light than ChR2, with the light sensitivity of HaloR being $\sim 20$-fold lower than that of ChR2. It remains to be determined whether the lower light sensitivity of HaloR is because of poor membrane targeting (Gradinaru et al., 2008; Zhao et al., 2008) or because of fundamental difference between ion channels and pumps (Hille, 2001).

The occurrence of HaloR-mediated rebound OFF responses is essential to restoring OFF responses in the retina. Our results indicate that the generation of the rebound OFF response is an intrinsic property of these cells. In addition, both sustained and transient OFF responses were observed. Interestingly, for sustained cells, the HaloR-mediated membrane hyperpolarization exhibited an initial large hyperpolarization followed by a relaxation. This property is characteristic of the activation of hyperpolarization-activated and cyclic nucleotide-gated ( $\mathrm{HCN})$ channels (Robinson and Siegelbaum, 2003), which has also been reported previously in retinal bipolar cells (Ma et al., 2003) and ganglion cells (Lee and Ishida, 2007). Our results suggest that the sustained rebound spike firing may be driven in part by $\mathrm{HCN}$ mediated currents. Other intrinsic membrane channels, however, could also be involved. Further studies will be required to examine the detailed underlying mechanism(s).
It remains unknown if the HaloR-mediated sustained and transient responses correspond to intrinsic sustained and transient cells. Intrinsic properties of retinal ganglion cells have been reported, in part, to underlie their light response properties (Diamond and Copenhagen, 1995; Tabata and Ishida, 1996; Margolis and Detwiler, 2007). Thus, it would be interesting for further studies to determine if there is a correlation between the HaloRmediated sustained and transient responses and the intrinsic sustained and transient retinal ganglion cells.

Importantly, similar to ChR2-mediated ON responses (Bi et al., 2006), our results show that HaloR-mediated OFF responses in ganglion cells are remarkably similar to the natural responses of OFF ganglion cells (Arkin and Miller, 1988; Nelson et al., 1993). Furthermore, our results show that HaloR-mediated responses can follow temporal modulation of light up to at least 10 $\mathrm{Hz}$ in inner retinal neurons of $r d 1 / r d 1$ mice. Thus, ChR2- and HaloR-mediated light responses could fulfill the fast temporal processing requirements of visual information in the degenerated retina.

The results of this study demonstrate, as proof of concept, two possible strategies to restore both $\mathrm{ON}$ and OFF responses in retinas after the death of rod and cone photoreceptors. First, this restoration could be achieved by targeting ChR2 and HaloR to intrinsic $\mathrm{ON}$ and OFF inner retinal neurons such as $\mathrm{ON}$ and $\mathrm{OFF}$ retinal bipolar cells or retinal ganglion cells, respectively. Cellspecific enhancers or promoters could be used for targeted delivery of ChR2 and HaloR to native ON and OFF cells (Ueda et al., 1997; Kim et al., 2008; Yonehara et al., 2008). Indeed, a recent study showed that targeting ChR2 to ON bipolar cells with a promoter of the Grm6 gene, which encodes mGluR6 receptors, by electroporation restored $\mathrm{ON}$ light responses to the retina, as 

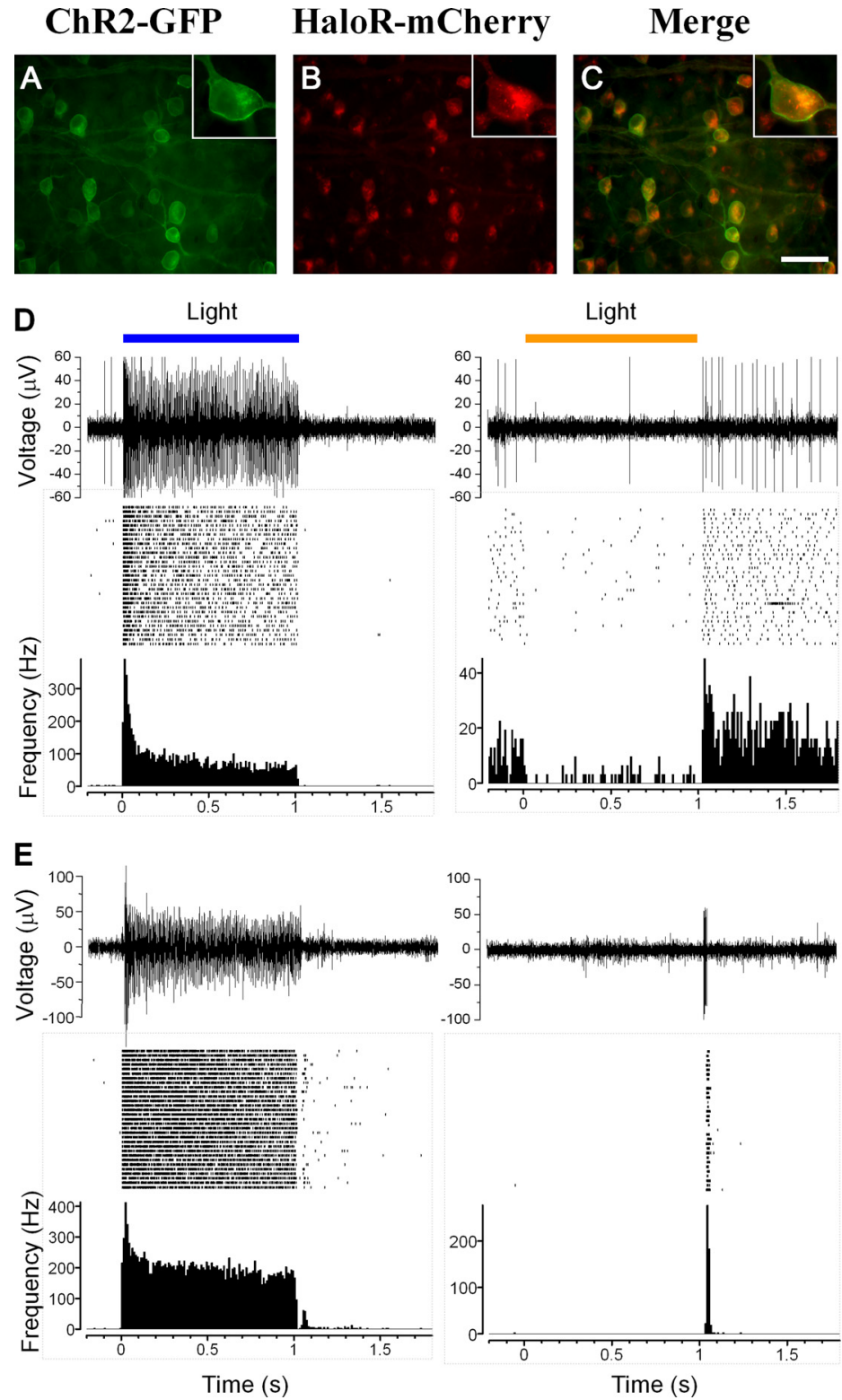
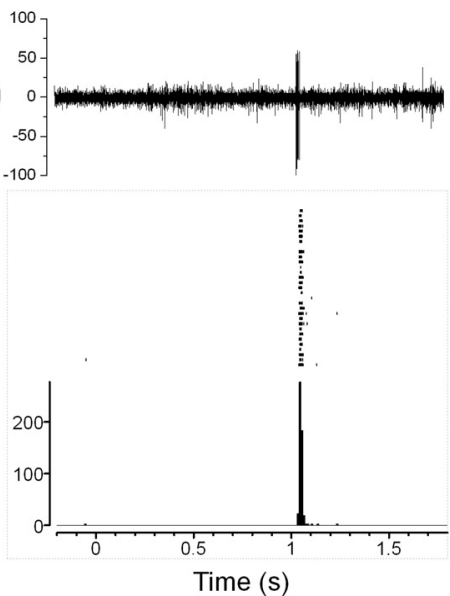

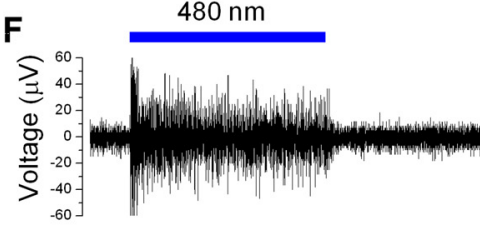

$520 \mathrm{~nm}$

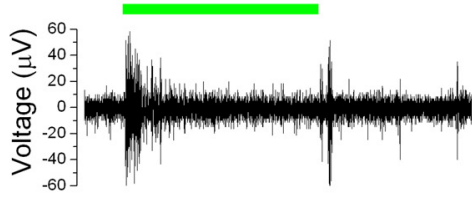

$530 \mathrm{~nm}$

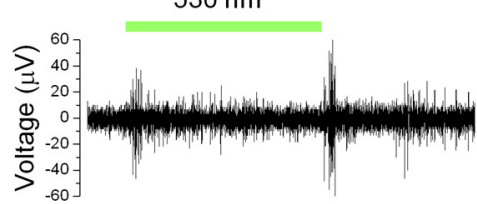

$580 \mathrm{~nm}$

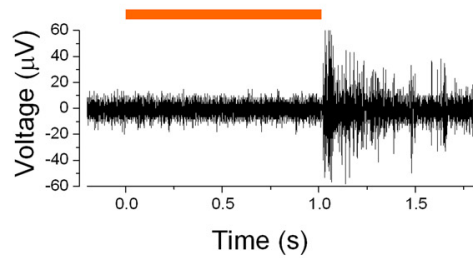

G

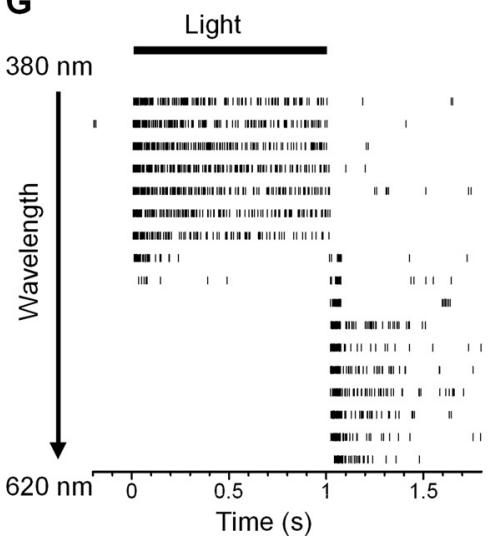

Figure 7. Multielectrode array recordings of the coexpression of HaloR/ChR2-mediated spike responses from $r d 1 / r d 1$ retinas. $\boldsymbol{A}-\boldsymbol{C}$, GFP $(\boldsymbol{A})$ and $\mathrm{mCherry}(\boldsymbol{B})$ fluorescence images were taken at the ganglion layer in retinal whole mounts. The two images are merged in $C$. Scale bar, $50 \mu \mathrm{m}$. Insets show a single cell at higher magnification. $\boldsymbol{D}, A$ representative recording is shown from a sustained cell in response to light at wavelengths of $460 \mathrm{~nm}$ (left) and $580 \mathrm{~nm}$ (right). In each panel, a single trace of spike activity, a raster plot, and an averaged spike rate histogram are shown. $\boldsymbol{E}$, A representative recording is shown from a transient cell in response to light at wavelengths of $460 \mathrm{~nm}$ (left) and $580 \mathrm{~nm}$ (right). G, Raw traces from a HaloR/ChR2 coexpressing cell in response to light for the four wavelengths of $480,520,530$, and $580 \mathrm{~nm}$. $\boldsymbol{F}$, The raster plot shows recordings from the same cell as in $\boldsymbol{G}$ in response to light at wavelengths ranging from 380 to $620 \mathrm{~nm}$ ( $380-520 \mathrm{~nm}$ and $580-620 \mathrm{~nm}$ in $20 \mathrm{~nm}$ increments; $520-580 \mathrm{~nm}$ in $10 \mathrm{~nm}$ increments). The light intensities at 460 and $580 \mathrm{~nm}$ in $\boldsymbol{D}$ and $\boldsymbol{E}$ were $6.6 \times 10^{16}$ and $4.8 \times 10^{16}$ photons $\mathrm{cm}^{-2} \mathrm{~s}^{-1}$, respectively.

well as certain visual behaviors, in $r d 1 / r d 1$ mice (Lagali et al., 2008).

As an alternative strategy, the restoration of both $\mathrm{ON}$ and $\mathrm{OFF}$ responses in the retina could be achieved by coexpressing ChR2 and HaloR in inner retinal neurons such as retinal ganglion cells. As demonstrated in this study, the response properties of a ChR2/ HaloR coexpressing cell could be controlled by the wavelength of light. Specifically, light with a wavelength of $\leq 500 \mathrm{~nm}$ could effectively elicit an ON response, whereas light with a wavelength $\geq 540 \mathrm{~nm}$ could elicit an OFF response from a ChR2/HaloR coexpressing cell. Our results also show that light with intermediate wavelengths of $\sim 520-530 \mathrm{~nm}$ could elicit an ON-OFF response. Thus, a single ChR2/HaloR coexpressing cell could act as an ON, $\mathrm{OFF}$, or even $\mathrm{ON}-\mathrm{OFF}$ cell, depending on the light wavelength that is projected onto the cell. One advantage of this strategy is that transgene expression can be achieved using ubiquitous promoters. It should be noted that for this latter strategy, an external image processing device coupled to patterned optical stimulation such as a laser scanner will be required to encode the light increment or decrement by light spectrum and precisely project it onto individual cells. Furthermore, an external image processing device will likely also be required for microbial rhodopsin-based approaches in general. As reported previously for ChR2 (Bi et al., 2006) and shown in this study for HaloR, both exhibit low-light sensitivity. The threshold light intensities required to activate ChR2 and HaloR are $\sim 5$ and $6 \log$ units higher than that for cone photoreceptors. In addition, as may be true for all microbial rhodopsins, ChR2 and HaloR have a limited light intensity operating 
range of 2-3 log units. To operate over the wide range of light intensities encountered in the natural environment, for clinical applications, an external image processing device could be used to compensate for the low-light sensitivity and narrow light operating range of ChR2 and HaloR.

In addition, the restoration of both $\mathrm{ON}$ and OFF responses may also be achieved by targeting the expression of ChR2 to certain populations of second- or third-order neurons. Targeting ChR2 to rod bipolar cells and AII amacrine cells is particularly attractive, because in mammals, including humans, the rod signal is relayed through rod bipolar cells to AII amacrine cells and then piggybacked onto ON and OFF cone pathways by gap junctions and glycinergic synapses, respectively (Bloomfield and Dacheux, 2001). One advantage of targeting ChR2 to these more distal inner retinal neurons is that this approach may partially preserve the inner retinal processing. In addition, it could achieve higher spatial resolution and increase light sensitivity because of signal convergence from bipolar cells onto retinal ganglion cells. However, this strategy will require the integrity of circuit and functional synapses from these more distal inner retinal neurons to retinal ganglion cells. Recent studies have reported that the morphological properties of second-order cells but not retinal ganglion cells are compromised in retinal degenerative mouse models, including $r d 1 / r d 1$ mice (Strettoi and Pignatelli, 2000; Gargini et al., 2007; Mazzoni et al., 2008). In such circumstances, restoration of $\mathrm{ON}$ and $\mathrm{OFF}$ responses in retinal ganglion cells would be the only option. Therefore, retinal ganglion cells could be a prime target for the optical stimulation-based approach.

Thus, our results suggest that the expression of microbial rhodopsins such as ChR2 and HaloR in surviving inner retinal neurons is a promising approach for restoring vision in patients who are blind caused by the loss of rod and cone photoreceptors. As demonstrated in this and previous studies (Bi et al., 2006), rAAVbased gene delivery systems are effective tools for introducing ChR2 and HaloR into inner retinal neurons. The long-term stability of $r \mathrm{AAV}$-mediated expression of ChR2 in retinal neurons has been demonstrated in animal models (Bi et al., 2006). Recently, rAAV vectors have been used in human clinical trials to treat other retinal degenerative diseases (Maguire et al., 2008). Further studies on the long-term safety of the expression of ChR2 and HaloR in animal models will be an important step for the development of clinical applications in human patients. Animal behavioral studies could be used to gain insights into the effectiveness of such treatments (Prusky et al., 2000, 2004; Lagali et al., 2008).

Transplantation of normal photoreceptor cells or progenitor cells (Bok, 1993; Lund et al., 2001; MacLaren et al., 2006) and electrical stimulation-based retinal implants (Zrenner, 2002; Weiland et al., 2005) are two other major approaches that are currently under study for the restoration of light responses in the retina after photoreceptor degeneration. A potential advantage of the optical stimulation-based approach is that it could largely avoid the complications of immune reactions and biocompatibility, while achieving high spatial resolution. In addition, as shown in this study, this approach could potentially restore both $\mathrm{ON}$ and OFF light responses to mimic natural visual information processing in the retina. Furthermore, targeting ChR2 and HaloR or their derivatives to different inner retinal neurons and/or their subcellular components may further improve the restoration of vision by reestablishing the features of spatial processing and even spectrum sensitivity to the degenerated retina.

\section{References}

Arkin MS, Miller RF (1988) Bipolar origin of synaptic inputs to sustained OFF-ganglion cells in the mudpuppy retina. J Neurophysiol 60:1122-1142.

Bi A, Cui J, Ma YP, Olshevskaya E, Pu M, Dizhoor AM, Pan ZH (2006) Ectopic expression of a microbial-type rhodopsin restores visual responses in mice with photoreceptor degeneration. Neuron 50:23-33.

Bloomfield SA, Dacheux RF (2001) Rod vision: pathways and processing in the mammalian retina. Prog Retin Eye Res 20:351-384.

Bok D (1993) Retinal transplantation and gene therapy. Present realities and future possibilities. Invest Ophthalmol Vis Sci 34:473-476.

Bowes C, Li T, Danciger M, Baxter LC, Applebury ML, Farber DB (1990) Retinal degeneration in the rd mouse is caused by a defect in the beta subunit of rod cGMP-phosphodiesterase. Nature 347:677-680.

Boycott B, Wässle H (1999) Parallel processing in the mammalian retina: the Proctor Lecture. Invest Ophthalmol Vis Sci 40:1313-1327.

Boyden ES, Zhang F, Bamberg E, Nagel G, Deisseroth K (2005) Millisecondtimescale, genetically targeted optical control of neural activity. Nat Neurosci 8:1263-1268.

Cui J, Ma YP, Lipton SA, Pan ZH (2003) Glycine receptors and glycinergic synaptic input at the axon terminals of mammalian retinal rod bipolar cells. J Physiol 553:895-909.

Diamond JS, Copenhagen DR (1995) The relationship between light evoked synaptic excitation and spiking behaviour of salamander retinal ganglion cells. J Physiol 487:711-725.

Farah N, Reutsky I, Shoham S (2007) Patterned optical activation of retinal ganglion cells. Conf Proc IEEE Eng Med Biol Soc 2007:6369-6371.

Gargini C, Terzibasi E, Mazzoni F, Strettoi E (2007) Retinal organization in the retinal degeneration 10 ( $\mathrm{rd} 10)$ mutant mouse: a morphological and ERG study. J Comp Neurol 500:222-2238.

Gradinaru V, Thompson KR, Deisseroth K (2008) eNpHR: a Natronomonas halorhodopsin enhanced for optogenetic applications. Brain Cell Biol 36:129-139.

Han X, Boyden ES (2007) Multiple-color optical activation, silencing, and desynchronization of neural activity, with single-spike temporal resolution. PLoS One 2:e299.

Hattar S, Liao HW, Takao M, Berson DM, Yau KW (2002) Melanopsincontaining retinal ganglion cells: architecture, projections, and intrinsic photosensitivity. Science 295:1065-1070.

Hille B (2001) Ionic channels of excitable membranes. Sunderland, MA: Sinauer.

Jacobs AL, Werblin FS (1998) Spatiotemporal patterns at the retinal output. J Neurophysiol 80:447-451.

Jiménez AJ, García-Fernández JM, González B, Foster RG (1996) The spatio-temporal pattern of photoreceptor degeneration in the aged $\mathrm{rd} / \mathrm{rd}$ mouse retina. Cell Tissue Res 284:193-202.

Jones BW, Watt CB, Frederick JM, Baehr W, Chen CK, Levine EM, Milam AH, Lavail MM, Marc RE (2003) Retinal remodeling triggered by photoreceptor degenerations. J Comp Neurol 464:1-16.

Kaneko A (1970) Physiological and morphological identification of horizontal, bipolar, and amacrine cells in the goldfish retina. J Physiol 207:623-633.

Kim DS, Matsuda T, Cepko CL (2008) A core paired-type and POU homeodomain-containing transcription factor program drives retinal bipolar cell gene expression. J Neurosci 28:7748-7764.

Kim IJ, Zhang Y, Yamagata M, Meister M, Sanes JR (2008) Molecular identification of a retinal cell type that responds to upward motion. Nature 452:478-482.

Kolbe M, Besir H, Essen LO, Oesterhelt D (2000) Structure of the lightdriven chloride pump halorhodopsin at $1.8 \mathrm{~A}$ resolution. Science 288:1390-1396.

Lagali PS, Balya D, Awatramani GB, Münch TA, Kim DS, Busskamp V, Cepko CL, Roska B (2008) Light-activated channels targeted to ON bipolar cells restore visual function in retinal degeneration. Nat Neurosci 11:667-675.

Lanyi JK (1986) Halorhodopsin: a light-driven chloride ion pump. Annu Rev Biophys Biophys Chem 15:11-28.

Lanyi JK, Duschl A, Hatfield GW, May K, Oesterhelt D (1990) The primary structure of a halorhodopsin from Natronobacterium pharaonis. Structural, functional and evolutionary implications for bacterial rhodopsins and halorhodopsins. J Biol Chem 265:1253-1260. 
Lee SC, Ishida AT (2007) Ih without Kir in adult rat retinal ganglion cells. J Neurophysiol 97:3790-3799.

Lund RD, Kwan AS, Keegan DJ, Sauvé Y, Coffey PJ, Lawrence JM (2001) Cell transplantation as a treatment for retinal disease. Prog Retin Eye Res 20:415-449.

Ma YP, Cui J, Hu HJ, Pan ZH (2003) Mammalian retinal bipolar cells express inwardly rectifying $\mathrm{K}^{+}$currents $\left(\mathrm{I}_{\mathrm{Kir}}\right)$ with a different distribution than that of $\mathrm{I}_{\mathrm{h}}$. J Neurophysiol 90:3479-3489.

MacLaren RE, Pearson RA, MacNeil A, Douglas RH, Salt TE, Akimoto M, Swaroop A, Sowden JC, Ali RR (2006) Retinal repair by transplantation of photoreceptor precursors. Nature 444:203-207.

Maguire AM, Simonelli F, Pierce EA, Pugh EN Jr, Mingozzi F, Bennicelli J, Banfi S, Marshall KA, Testa F, Surace EM, Rossi S, Lyubarsky A, Arruda VR, Konkle B, Stone E, Sun J, Jacobs J, Dell'Osso L, Hertle R, Ma JX, et al. (2008) Safety and efficacy of gene transfer for Leber's congenital amaurosis. N Engl J Med 358:2240-2248.

Margolis DJ, Detwiler PB (2007) Different mechanisms generate maintained activity in ON and OFF retinal ganglion cells. J Neurosci 27:5994-6005.

Mazzoni F, Novelli E, Strettoi E (2008) Retinal ganglion cells survive and maintain normal dendritic morphology in a mouse model of inherited photoreceptor degeneration. J Neurosci 28:14282-14292.

McLaughlin ME, Sandberg MA, Berson EL, Dryja TP (1993) Recessive mutations in the gene encoding the beta-subunit of rod phosphodiesterase in patients with retinitis pigmentosa. Nat Genet 4:130-134.

Nagel G, Szellas T, Huhn W, Kateriya S, Adeishvili N, Berthold P, Ollig D, Hegemann P, Bamberg E (2003) Channelrhodopsin-2, a directly lightgated cation-selective membrane channel. Proc Natl Acad Sci U S A 100:13940-13945.

Nelson R, Kolb H, Freed MA (1993) OFF-alpha and OFF-beta ganglion cells in cat retina. I: Intracellular electrophysiology and HRP stains. J Comp Neurol 329:68-84.

Pan ZH (2000) Differential expression of high- and two types of lowvoltage-activated calcium currents in rod and cone bipolar cells of the rat retina. J Neurophysiol 83:513-527.

Prusky GT, West PW, Douglas RM (2000) Behavioral assessment of visual acuity in mice and rats. Vision Res 40:2201-2209.

Prusky GT, Alam NM, Beekman S, Douglas RM (2004) Rapid quantification of adult and developing mouse spatial vision using a virtual optomotor system. Invest Ophthalmol Vis Sci 45:4611-4616.

Rentería RC, Tian N, Cang J, Nakanishi S, Stryker MP, Copenhagen DR (2006) Intrinsic ON responses of the retinal OFF pathway are suppressed by the ON pathway. J Neurosci 26:11857-11869.

Robinson RB, Siegelbaum SA (2003) Hyperpolarization-activated cation currents: from molecules to physiological function. Annu Rev Physiol 65:453-480.

Schiller PH, Sandell JH, Maunsell JHR (1986) The functions of the ON and OFF channels of the visual system. Nature 322:824-825.

Seki A, Miyauchi S, Hayashi S, Kikukawa T, Kubo M, Demura M, Ganapathy
V, Kamo N (2007) Heterologous expression of Pharaonis halorhodop$\sin$ in Xenopus laevis oocytes and electrophysiological characterization of its light-driven Cl- pump activity. Biophys J 92:2559-2569.

Shaner NC, Campbell RE, Steinbach PA, Giepmans BN, Palmer AE, Tsien RY (2004) Improved monomeric red, orange and yellow fluorescent proteins derived from Discosoma sp. red fluorescent protein. Nat Biotechnol 22:1567-1572.

Stasheff SF (2008) Emergence of sustained spontaneous hyperactivity and temporary preservation of OFF responses in ganglion cells of the retinal degeneration ( $r d 1)$ Mouse. J Neurophysiol 99:1408-1421.

Strettoi E, Pignatelli V (2000) Modifications of retinal neurons in a mouse model of retinitis pigmentosa. Proc Natl Acad Sci U S A 97:11020-11025.

Tabata T, Ishida AT (1996) Transient and sustained depolarization of retinal ganglion cells by Ih. J Neurophysiol 75:1932-1943.

Tian N, Copenhagen DR (2003) Visual stimulation is required for refinement of ON and OFF pathways in postnatal retina. Neuron 39:85-96.

Tomita H, Sugano E, Yawo H, Ishizuka T, Isago H, Narikawa S, Kügler S, Tamai M (2007) Restoration of visual response in aged dystrophic RCS rats using AAV-mediated channelopsin-2 gene transfer. Invest Ophthalmol Vis Sci 48:3821-3826.

Tu DC, Zhang D, Demas J, Slutsky EB, Provencio I, Holy TE, Van Gelder RN (2005) Physiologic diversity and development of intrinsically photosensitive retinal ganglion cells. Neuron 48:987-999.

Ueda Y, Iwakabe H, Masu M, Suzuki M, Nakanishi S (1997) The mGluR6 5' upstream transgene sequence directs a cell-specific and developmentally regulated expression in retinal rod and ON-type cone bipolar cells. J Neurosci 17:3014-3023.

Wässle H (2004) Parallel processing in the mammalian retina. Nat Rev Neurosci 5:747-757.

Weiland JD, Liu W, Humayun MS (2005) Retinal prosthesis. Annu Rev Biomed Eng 7:361-401.

Weleber RG (1994) Retinitis pigmentosa and allied disorders. In: Retina (Ryan SJ, ed), pp 335-466. St. Louis: Mosby.

Werblin FS, Dowling JE (1969) Organization of the retina of the mudpuppy, Necturus maculosus. II. Intracellular recording. J Neurophysiol 32:339-355.

Yonehara K, Shintani T, Suzuki R, Sakuta H, Takeuchi Y, NakamuraYonehara K, Noda M (2008) Expression of SPIG1 reveals development of a retinal ganglion cell subtype projecting to the medial terminal nucleus in the mouse. PLoS ONE 3:e1533.

Zhang F, Wang LP, Brauner M, Liewald JF, Kay K, Watzke N, Wood PG, Bamberg E, Nagel G, Gottschalk A, Deisseroth K (2007) Multimodal fast optical interrogation of neural circuitry. Nature 446:633-639.

Zhao S, Cunha C, Zhang F, Liu Q, Gloss B, Deisseroth K, Augustine GJ, Feng G (2008) Improved expression of halorhodopsin for light-induced silencing of neuronal activity. Brain Cell Biol 36:141-154.

Zrenner E (2002) Will retinal implants restore vision? Science 295:10221025. 